\title{
Gaixotasun traumatikoa eta trauma-sistemak
}

\section{Trauma disease and trauma systems}

Iker Garcia Saez

Medikuntza Intentsiboko Zerbitzua. Donostia Unibertsitate Ospitalea.

iker.garciasaez@osakidetza.eus

\section{Laburpena}

Osasunaren Mundu Erakundearen (OME) esanetan, traumatismoen ondorioz urtero 4 milioi pertsona baino gehiago hiltzen dira eta dozenaka milioi zauritzen. Arrisku-faktoreak ez daude gizabanakoen jokabidearekin lotuta bakarrik, pisuzkoak dira ere aldagai soziosanitario, laboral, ekonomiko, politiko eta kulturalak. Izan ere, azken urteotan, medikuntza modernoaren eta baliabide teknologikoen garapenarekin batera, paziente traumatikoen arretan emaitzak nabarmenki hobetu dira herrialde garatuetan. Baliabideen erabilera egokia eta azpiegitura logistikoaren antolaketa funtsezkoak izan dira hobekuntza horretan. Eta, hain zuzen ere, hauxe da Trauma Sistema ideiaren jatorria: paziente traumatikoen beharrak berdinak izaten dira eskura dauden baliabideak direnak direla; ordea, zentro guztiek ez dituzte eskuragarri atentzio egoki eta osorako behar diren baliabide guztiak. Errealitate horrek Trauma Sistema baten barnean antolatzera bultzatzen ditu zentrook. Ildo honi jarraituz, Gipuzkoako Trauma Sistemak gure lurraldean dauzkagun zentroak integratzen ditu, emergentziekin batera, ondo lotutako sare baten barnean. Era berean, Gipuzkoako Trauma Batzordea osatu zen 2010. urtean, espezialitate ezberdinen kideak biltzen dituena. Orduz geroztik, hainbat ekimen bultzatu dira paziente traumatikoaren atentzioa hobetzeko asmoz, azken hamarkadan ingresatutako traumatizatu larrien hilkortasuna \% 16,7tik \% 8,77ra jaitsi delarik gure lurraldean. Horrenbestez, argi geratzen da Trauma Sistemak erreminta baliagarriak direla eskura dauden baliabideak modu egokian kudeatzeko eta zauritutako pazienteei atentziorik onena emateko.

Gako-hitzak: gaixotasun traumatikoa; traumatismoa; politraumatismoa; trauma-sistema; traumabatzordea

\section{Abstract}

According to the World Health Organization (WHO), every year there are over 4 million deaths due to traumatisms, and dozens of millions of people are injured. Risk factors are not only associated with the behavior of individuals, but also with socio-sanitary, occupational, economic, political and cultural variables, which exert a significant influence. Indeed, in high-income regions, along with the development of modern medicine and technology, results have dramatically improved in recent years. The appropriate use of resources and the management of logistic infrastructure have been essential in this regard. And this is the origin of the idea of Trauma Systems: the needs of patients with trauma are the same wherever they are, independent of the available resources; however, not all facilities have all the necessary resources to give appropriate and thorough attention. This reality has encouraged facilities to organize themselves within Trauma Systems. Along these lines, the Gipuzkoa Trauma System integrates all the Health Centres of our region, as well as emergency services, into one unique system. Likewise, the Gipuzkoa Trauma Commission, which is made up of members with different specialties, was established in 2010. Since then, many initiatives have been promoted to improve the attention of patients with trauma and, as a result, the mortality of severe cases admitted to hospital has decreased from 16.7 to $8.8 \%$ in our region. Therefore, it is clear that 
Trauma Systems are valuable tools for the appropriate management of available resources and for the optimal care of injured patients.

Key-words: trauma disease; traumatism; polytraumatism; trauma system; trauma board

Bidalia: 2018-04-16

Onartua: 2018-11-10

http://doi.org/10.26876/osagaiz.2.2018.145

\section{Sarrera: «Arretarik gabeko epidemia»}

Osasunaren Mundu Erakundearen (OME) esanetan, traumatismoen ondorioz urtero 4 milioi hildako baino gehiago eta dozenaka milioi zauritu gertatzen dira. Izan ere, Global Burden of Disease Study (1) (2) ikerketan argitaratutako azken datuen arabera, minutu bakoitzeko 9 hildako suertatzen dira bai istripuetan bai indarkeriaren ondorioz, eta 2015. urteko heriotzen \% 10,14 kausa traumatikoengatik izan ziren (talde bezala, prebalentzia handiko beste eritasun askoren aurretik jarriz, esaterako HIESa, zirrosia eta tuberkulosia) (1-3).

Medikuntza modernoaren garapenak, eta zientziarenak oro har, aurrerapen teknologikoen laguntzarekin batera, lesio traumatikoei aurre egiteko baliabideak hobetu ditu. Gaur egun, paziente traumatikoa arreta emateko ikuspegi berezia eta sistematizatua erabiltzen da, lesiorik larrienak detektatu eta lehenbailehen konpontzeko helburuarekin. Halaber, baliabide tekniko eta metodologiko berriek ildo berari jarraitzen diote: Ordenagailu Bidezko Tomografia Axialak (OTA) diagnostiko zehatza egiteko denbora nabarmenki murriztu du, Kalteen Kontrolerako Kirurgia (Damage Control Surgery) lesio larrienen lehentasunezko tratamenduan oinarritzen da, eta, azkenik, Erradiologia Interbentzionistak hemorragien konponbide azkarra eta eraginkorra ahalbidetu du.

Zalantzarik gabe beraz, azken urteotan paziente traumatikoen atentzioan emaitzak nabarmenki hobetu dira herrialde garatuetan; eta hala eta guztiz ere, esandako nazioetan heriotza-kausa nagusia izaten jarraitzen du 5 eta 49 urte bitarteko pertsonen artean.

Baker-ek "arretarik gabeko epidemia» izendatu zuen 1985. urtean (4), eta datuok arazoaren dimentsioa adierazten dute, proportzio epidemikoak izatera heldu dena. Baina problema are handiagoa bihurtzen da ondorio sozialak aztertzerakoan, gizartearen bizilagun gazte eta potentzialki produktiboenak jotzen baititu bereziki (5).

\section{Epidemiologia. Neurriak eta baliabideak}

Traumatismoek pandemia bat eragiten dute, eta heriotza- zein morbilitate-kausa nagusien artean daude.

Arrisku-faktoreak baina, ez daude gizabanakoen jokabidearekin lotuta bakarrik, pisuzkoak dira ere aldagai soziosanitario, laboral, ekonomiko, politiko eta kulturalak (6).

Garraiobideetan gertatutako istripuek traumatismoen ondoriozko heriotzen \% 29 eragiten dituzte. 2016. urtean 1,4 milioi pertsona hil ziren trafiko-istripuetan, hau da, egunero ia 4.000 gizabanako inguru hil ziren errepideetan (1) (2). Gure lurraldean kopuru hori murriztea lortu dugu, prebentzioan zein atentzioan ezarritako neurriei esker: horien artean daude, besteak beste, errepideen hobekuntza eta ibilgailuen aurrerabideak segurtasunaren aldetik, lege berrien garapena eta populazioa kontzientziatzeko mezuak komunikabideetan, eta atentziorako sare integratua osatzea. Eta horiei esker, azken urteotan beheranzko joera bat ikusi izan dugu, bai gertatutako istripu larrietan, baita hildako zein larriki zauritutakoetan ere. 2002. urtean, aldiz, 5.747 istripu gertatu ziren Gipuzkoako errepideetan, 65 hildakorekin; aldiz, 2016. urtean 3.529 istripu izan ziren, eta 14 hildako bakarrik (7). Bestetik, milurteko berriaren hasieran gaixo traumatiko larrien $\% 70$ inguru trafikoistripuen ondoriozkoak izaten ziren eta, gaur egun, \% 50ean kokatzen da haien kopurua (\% 40-50 artean finkatu da portzentaje hori azken bosturtekoan). Horrez gain, gaixo hauen hilkortasuna 
nabarmenki jaistea lortu dugu azken urteotan, milurtekoa hasi aurretik, traumatismo larrien ondorioz ospitalean hiltzen zirenen $\% 60$ gainditzen baitzuten trafiko-istripuek, eta gaur egun \% 25era bakarrik ailegatzen dira.

Aldiz, ustekabeko erorketak garrantzia geroz eta handiagoa hartzen ari dira. Alde batetik, haien maiztasuna igotzen ari da eta, bestetik, pertsona adinduen artean gertatzen dira bereziki, hilkortasuna handia izanik talde horretan. Izan ere, 70-75 urtetik aurrera, hauxe da traumatismoen ondoriozko heriotza-arrazoi nagusia mundu mailan (1-3). Gipuzkoan, azken urteotan joera hori finkatuz joan da, eta 2016. urtean traumatismo larrien \% 30 erorketen ondorioz gertatu ziren, proportzio hori handiagoa izanik nagusien artean. Halaber, ustekabeko erorketen ondorioz zauritutakoen batez besteko adina handiagoa da, gainontzekoekin alderatuz.

Baliabide teknikoen garapenari dagokionez, aipagarria da kalteen kontrolerako kirurgiak (Damage Control Surgery) eta, batez ere, erradiologia interbentzionistak bereganatu duten protagonismoa.

2010. urtean Donostia Unibertsitate Ospitalean 8 arteriografia egin zitzaizkien gaixo traumatikoei, eta zenbaki hori handituz joan da, 2016an 17 egin zirelarik. Enbolizazioek lesio hemorragiko askoren pronostikoa nabarmenki hobetu dute, heriotza-tasa eta morbilitatea ez ezik, egonaldiak, konplikazioak eta, ondorioz, kostuak ere murrizten baitituzte aukeratutako kasuetan.

\section{Trauma Sistemak eta Trauma Batzordeak}

1983. urtean argitaratutako lanean, Trunkey eta bere laguntzaileek heriotzen banaketa trimodala deskribatu zuten (8) (9): heriotzen lehenengo multzo bat aurreneko minutuetan gertatzen da, airebideak, sistema zirkulatorioa edota nerbio-sistema zentrala larriki kaltetuak izatearen ondorioz; bigarren talde bat ordu batzuen epean gertatzen da, hauen artean hemorragiak nabarmenduz; eta hirugarren talde bat egun edo asteak igarota, disfuntzio multiorganikoaren ondorioz.

Adierazgarria da talde horien banaketa eta konposizioa ezberdina izaten dela baliabideen arabera. Alegia, erakunde bakoitzaren baliabide eta antolaketaren arabera, zenbakiak aldatzen dira (5). Eta, hain zuzen ere, baliabideen erabilera egokia eta azpiegitura logistikoaren antolaketa izan dira Trauma Sistema ideiaren jatorria (10): ospitale kanpoko zein larrialdietako atentzioan Trauma Taldeak trebatzea, programaren lerroak definitu eta protokoloak prestatzea, Trauma Zentroak izendatu eta definitzea, egitura eta baliabideen egokitzea, eta zaurituen garraiorako logistika antolatzea dira Trauma Sistema egituratzen duten ardatzak.

Azken urteotan traumatismoengatiko hilkortasuna jaitsi egin da. Eta jaitsiera horretan, esan bezala, atentzioaren eta antolaketa sanitarioaren inguruko faktoreek ez ezik, azpiegituretan egindako hobekuntzek eta hezkuntza-arloan zein legedian izandako ekimenek ere izan dute zerikusia (11). Eta ez da gutxi, beharbada prebentzioan dagoelako erronkarik handiena.

Zentzu horretan, prebentzioaren arloan edozein ekintza gauzatzeko, ezinbestekoa da aldez aurretik egoera ondo ezagutzea, hau da, egindako lana eta emaitzak aztertzea, akatsak antzeman eta zuzentzeko. Baita hobetu daitezkeen esparruei baliabideak bideratzeko ere eta, oro har, sistemaren beharrak asetzeko (12). Horretarako, alde batetik datuek eskuragarri egon behar dute eta, zentzu horretan, ezinbestekoa da Trauma Erregistro bat edukitzea (13). Bestetik, datuok aztertzeko zein ondorioak lantzeko erakunde edo organismo bat izendatu beharra dago. Eta organismo hori Trauma Batzordea da.

Aipatu bezala, Trauma Sistema batek zenbait osagai ditu, eta horiek bildu, lotu eta koordinatzen dituen lantaldea da Trauma Batzordea. Azken horrek, baliabide guztiak izan behar ditu estrategiak garatzeko, eta eskumena horiek ezartzeko, betiere landutako programen jarraipena ziurtatuz eta haien betetze egokia bermatuz (14) (15). Beraz, Trauma Batzordearen lan-esparrua ez da asistentziara bakarrik mugatzen, prebentzioan ere parte-hartze aktiboa izaten baitu.

Traumatismoek zama handia dakarkiote gizarteari, bai eremu sanitarioan baita ekonomikoan ere (4); eta zama hori gutxitzea zeregin konplexua da oso, ikuspegi zabala eta elkarlan koordinatua izan 
behar dituelako oinarri. Zauritutako paziente baten atentzioa prozesu bat da, eta lortutako emaitzan prozesu horretan zehar egiten diren ekintza guztiek dute garrantzia, hasierako atentziotik hasiz eta errehabilitazioan bukatuz. Horregatik, Trauma Batzordeak espezialitate ezberdinetako kideak biltzen ditu, taldeko ikuspegia eta elkarlana bultzatzeko.

\section{Gipuzkoako Trauma Sistema}

Paziente traumatikoen beharrak berdinak izaten dira, eskura dauden baliabideak direnak direla. Ordea, zentro guztiek ez dituzte eskuragarri atentzio egoki eta osorako behar diren baliabide guztiak; eta errealitate honek Trauma Sistema baten barnean antolatzera bultzatzen ditu zentrook (10).

Ildo horretan, Gipuzkoako Trauma Sistemak gure lurraldean dauzkagun zentroak integratzen ditu, emergentziekin batera, ondo lotutako sare baten barne. Eta sare horren erdian kokatzen da Donostia Unibertsitate Ospitalea, zeinak baliabide guztiak eskura dituen larriki zauritutako gaixoek dituzten behar guztiei aurre egiteko.

Era berean, Gipuzkoako Trauma Batzordea dago osatua, espezialitate ezberdinetako kideak biltzen dituena: Kirurgia Orokorra, Urologia, Traumatologia, Pediatria, Ginekologia, Anestesia, Erradiologia, Neurokirurgia, Hematologia, Medikuntza Intentsiboa, Errehabilitazioa, Larrialdiak eta ospitale kanpoko Emergentziak ere. Eta horiekin batera, Erizaintzaren arduradunak eta Zuzendaritzaren ordezkariak ere dira partaide.

Gipuzkoako Trauma Batzordea 2010. urtean sortu zen Orduz geroztik, hainbat ekimen bultzatu ditu paziente traumatikoaren atentzioa hobetzeko asmoz. Hilero biltzen dira partaideak Donostia Unibertsitate Ospitalean, eta, datuak aztertzeaz gain, gure sistema eguneratua mantentzeko azkeneko argitalpen eta joerak eztabaidatu eta haien ezartzea baloratzen du. Halaber, programak garatu eta ikastaroak antolatzen ditu, sistemaren parte diren profesional guztiei zuzenduak, adostutako jarraibideak eta protokoloak ezagutarazi eta haien betetzea ziurtatzeko.

Ondorioz, gure lurraldean zauritutako pazienteei punta-puntako atentzioa ematen zaie. Eta zenbakiek hala adierazten dute: azkenengo hamarkadan, ospitalean ingresatutako traumatizatu larrien hilkortasuna \% 16,7tik (2010. urtean) \% 8,77ra (2016an) jaitsi da gure lurraldean, Espainia mailan \% 15 inguruan mantentzen delarik (16).

Horrenbestez, eta ikusi bezala, Trauma Sistemak erreminta baliagarriak dira eskura dauden baliabideak modu egokian kudeatzeko eta zauritutako pazienteei atentziorik onena emateko.

\section{Erreferentzia bibliografikoak}

1. GBD 2015 Mortality and Causes of Death Collaborators. Global, regional, and national life expectancy, all-cause mortality, and cause-specific mortality for 249 causes of death, 1980-2015: a systematic analysis for the Global Burden of Disease Study 2015. Lancet 2016; 388: 1459-544.

2. Institute for Health Metrics and Evaluation. Global Burden of Disease (GBD). Seattle, WA: University of Washington; c2018 [Kontsulta 2018-08-31]. Eskuragarri: http://www.healthdata.org/gbd

3. Organización Mundial de la Salud. Informe sobre la situación mundial de la seguridad vial 2015 (http://www.who.int/violence injury prevention/road traffic/es/).

4. Baker S. Injuries: The Neglected Epidemic: Stone Lecture, 1985 American Trauma Society Meeting. J Trauma. 1987; 27: 343-8.

5. American College of Surgeons. Committee on Trauma. Advanced Trauma Life Support Student Course Manual. 9 argit. Chicago, IL: American College of Surgeons, 2012.

6. Alberdi F, García-Sáez I, Atutxa L, Zabarte M y Grupo de Trabajo de Trauma y Neurointensivismo de SEMICYUC. Epidemiología del trauma grave. Med Intensiva. 2014; 38(9): 580-588. 
7. Trafiko Istripuen Urtekari Estatistikoa. Eusko Jaurlaritza, Segurtasun Saila. Eskuragarri:https://www.trafikoa.eus/wps/PA_TNAnuario/html/view/web/docs/2017/eu/pdf/Tr afiko-2017-eu.pdf

8. Trunkey DD. Trauma. Accidental and intentional injuries account for more years of life lost in the U.S. than cancer and heart disease. Among the prescribed remedies are improved preventive efforts, speedier surgery and further research. Sci Am. 1983; 249(2): 28-35.

9. Trunkey DD, Blaisdel FW: Epidemiology of Trauma. Hemen: Scientific American Medicin, Care of the Surgical Patient. Wilmore DW, Brennan MF, Harken AH, et al. (Eds). New York Scientific American, 1993.

10. Resources for Optimal Care of the Injuried Patient 2014. American College of Surgeons, 2014.

11. Dijink S, Nederpelt CJ, Krijnen P, Velmahos GC, Shipper IB. Trauma Systems around the world: a systematic overview. Journal of Trauma and Acute Care Surgery. 2017, 83(5): 917-925.

12. Fernández Mondéjar E, Álvarez FJ, González Luque JC. Retos asistenciales en la atención al paciente traumatizado en España. La necesidad de implementación de la evidencia científica incluyendo la prevención secundaria. Med Intensiva. 2014; 38(6): 386-390.

13. Chico Fernández M, García Fuentes $C$, Guerrero López F. Registros en trauma: una prioridad sanitaria, un proyecto estratégico para la SEMICYUC. Med Intensiva. 2013; 37(4): 284-289.

14. Rucholtz S, Lefering R, Lewan V, Debus F, Mand C, Siebert H, et al. Implementation of a nationwide trauma network for the care of severely-injured patients. J Trauma Acute Care Surg. 2014; 76: 1456-61.

15. McCrum ML, McKee J, Lai M, Staples J, Switzer N, Widder SL. ATLS adherence in the transfer of rural trauma patients to a level I facility. Injury. 2013; 44: 1241-5.

16. Chico Fernández M, Llompart Pou JA, Guerrero López F, Sánchez Casado M, García Sáez I, Mayor García MD, Egea Guerrero J, Fernández Ortega JF, Bueno González A, González Robledo J, Servià Goixart L, Roldán Ramírez J, Ballesteros Sanz MA, Tejerina Álvarez E, García Fuentes C, Alberdi Odriozola F. Grupo de Trabajo de Trauma y Neurointensivismo SEMICYUC. Epidemiología del trauma grave en España. REgistro de TRAuma en UCI (RETRAUCI). Fase piloto. Med Intensiva. 2016; 40(6): 327-347. 
Iker Garcia Saez 